\title{
ENTENDIENDO LA RELEVANCIA DE LA INVESTIGACIÓN ACADÉMICA EN EL MUNDO EMPRESARIAL
}

Entre los principales objetivos de la Revista Empresarial, se encuentra el dirigir esfuerzos a entender cómo el contenido publicado ayuda a mejorar cada vez más el alcance y la relevancia de las investigaciones en el campo tan amplio de las ciencias sociales y administrativas. Después de observar que dentro de las posibilidades de investigación se encuentran diversas temáticas - que a breve rasgos me permito mencionar: administración, mercadeo, turismo, comercio, entre otras - se puede condensar estos tópicos y determinar que la labor de investigación se dirige y es inspirada en las situaciones actuales de cualquier tipo de organización y empresa. El enfoque que se plantea es entonces, todo aquello dirigido a la clarificación de estrategias gerenciales u organizacionales. Después de todo, nuestra sociedad es una gran organización en sí mismo.

Para sorpresa de muchos, y como los investigadores en el campo social y organizacional se podrán haber dado cuenta, la relevancia de la investigación organizacional - y todos sus posibles tópicos - no es fácil de reivindicar. Constantemente se ha puesto en debate cuán grande puede llegar a ser la brecha entre la investigación teórica y la práctica.

Con esta pequeña contrariedad y después de examinar con algo de detenimiento entre las numerosas publicaciones de una de las revistas académicas con más renombre en el mundo - Academy of Management - descubrí contenidos que nos reafirma y nos permite mantener la inspiración para continuar en el camino de la investigación académica. Entre todo ello, la publicación "I shall not remain insignificant" de Freek Vermeulen, catedrático de London Business School, llamó mi atención. En su artículo, Vermeulen dice acertadamente que la relevancia se encuentra en la generación de conocimientos y perspectivas que los profesionales encuentren útiles para comprender sus propias organizaciones y distintas situaciones mejor que antes. El autor manifiesta que la investigación académica no pretende dar recetas que resulten en el incremento en un $\mathrm{X} \%$ de la rentabilidad de la organización, sino que Vermeulen nos dice que: "personalmente, si al contarles a los profesionales sobre mi investigación y como resultado algunas de estas personas sienten que han obtenido una idea que aún no tenían, una que les permite tomar mejores decisiones con respecto a sus propias situaciones específicas de la empresa, siento que he hecho mi trabajo y mi investigación ha sido pertinente" (Vermeulen, 2007, p. 755).

El acierto de la bondad en su forma de ver a la academia se puede corroborar en su trayectoria con trabajos que nos permiten palpar la vinculación entre la academia y la empresa, en cada una de sus publicaciones en revistas del mayor prestigio, tales como Administrative Science Quarterly, The Academy of Management Journal, Organization Science, y the Strategic Management Journal, pero también en varios boletines gerenciales como Harvard Business Review, Sloan Management Review, The Financial Times, y The Wall Street Journal.

Pero no es fácil lograr esta virtud de estrechar los lazos academia-empresa. Vermeulen sostiene que para ello es necesario el constante reconocimiento de la meta de importar más, de volverse relevante, de hacer que importe.

Un último pensamiento de Vermeulen nos deja saber que una parte esencial es el involucramiento y la cercanía con las personas en la empresa. Es clave el intento permanente de comunicar, transferir y acercarse con la investigación a la empresa. Solo una pequeña demostración de este compromiso genuino permitirá que la investigación académica sea útil para las personas al frente de las organizaciones, individuos que se esfuerzan por dirigir a los grupos de personas que llamamos empresas a través de una realidad compleja y desordenada, para crear riqueza y, al final del día, un mundo mejor. Claro, este proceso de vinculación requerirá un poco de esfuerzo personal del investigador. Se necesita coraje para avanzar en el camino espinoso hacia la relevancia y se necesita alegría para disfrutar y sostener verdaderamente el viaje y la interacción laboriosa de la investigación con el mundo real de las organizaciones. 